\title{
The Epistemology of No Platforming: Defending the Defense of Stupid Ideas on University Campuses ${ }^{1}$
}

\section{Michael Veber}

East Carolina University; veberm@ecu.edu

Submitted: 18 September 2020, accepted: 21 March 2021, published: 25 April 2021

\begin{abstract}
No platforming is the practice of preventing or prohibiting someone from contributing to public discussion because that person advances what are-or are thought to be-objectionable views. Some of the most newsworthy cases of no platforming occur on university campuses. Despite what others have claimed, there are no good epistemic reasons for no platforming in that context.
\end{abstract}

Keywords: no platforming; campus speech; epistemology of free speech; following the argument where it leads; epistemic paternalism; academic freedom

How to cite: Veber, M. The Epistemology of No Platforming: Defending the Defense of Stupid Ideas on University Campuses. Journal of Controversial Ideas 2021, 1(1), 6; doi:10.35995/jci01010006.

(C) 2021 Copyright by the author. This article is an open access article distributed under the terms and conditions of the Creative Commons Attribution (CC BY 4.0) license.

(c) (1)

\section{Introduction}

No platforming is the practice of preventing or prohibiting someone from contributing to public discussion because that person advances what are-or are thought to be-objectionable views. Some of the most newsworthy cases of no platforming occur on university campuses. In this context, no platforming amounts to preventing someone from publicly speaking either by disrupting the event or refusing to allow it to be scheduled in the first place. The purpose of this paper is to assess whether there are any strong epistemological reasons for no platforming on university campuses.

Although epistemic reasons for no platforming are regularly offered, other justifications tend to get more attention with moral considerations being the most prominent. In 2015, people at Cardiff University petitioned to rescind Germaine Greer's invitation to speak on campus because of her position on transgender women.

\footnotetext{
I thank three anonymous referees at this journal for helpful comments and criticisms. The paper also benefitted from discussions with the following people (some have chosen to be acknowledged under a pseudonym): Lothar Bainbridge, Geddy R. Case, Brett Coppenger, John Eternal, Ed Erwin, Bas Fantell, Donny Hubcap, Ph.D., Thomas Kelly, A.J. Kreider, Jonathan Matheson, Ted Poston, and Josh Smith.
} 
The (ultimately unsuccessful) petition claimed Greer's views "contribute to the high levels of stigma, hatred, and violence toward trans people." In a time when budgets threaten the existence of faculty positions and even entire departments, practical reasons for no platforming can also carry significant weight. The University of California at Berkeley spent 3.9 million dollars in additional security costs for its 2017 "Free Speech Week"-an event that never actually took place. ${ }^{3}$

Oftentimes, reasons for no platforming are mixed. In 2018, Steve Bannon was invited to the University of Chicago to participate in a public debate over various issues of national interest. In response, 122 Chicago faculty signed a letter to the President and Provost arguing that Bannon should not be permitted to speak on campus. The letter included both the moral claim that Bannon engages in hate speech that demeans and dehumanizes marginalized people and the epistemic claim that his political positions "represent neither reasonable speech nor evidence-based and rigorous intellectual inquiry." "Other famous targets of no platforming campaigns-anti-vaxxers, Sandy Hook conspiracy theorists, and Holocaust deniers, for instance-are also subject to both moral and epistemic criticism.

Since the focus here is epistemic, it helps to find an example with minimal moral and practical implications. The Flat Earth Society is a community devoted (apparently in earnest) to promoting the notion that our home planet is a giant disc. If science enables us to know anything, we know this is false. But suppose (for reasons that will soon be clear) someone suggests inviting a flat earther to campus to defend this astronomically stupid theory. Thinking about this example provides a helpful way to isolate the epistemic reasons for and against no platforming. Unlike other targets of no platforming, the flat earther is generally regarded as a relatively benign goofball. We can set aside practical concerns about wasted resources by imagining the flat earther is willing to come to campus for free and on a day when nothing else is scheduled.

The overall argument of this paper will proceed as follows. I will consider several different epistemological justifications for no platforming in this hypothetical case. And I shall argue that each is weak and unpersuasive. Then, I will extend the argument from flat Earth theory to other prominent stupid ideas and argue that there is no strong epistemic reason to no platform in those cases either.

Before proceeding to the main argument, it will help to get clearer on what no platforming is and how the idea that there are strong epistemic reasons in favor of it will be understood. No platforming is a type of content-based regulation of speech. Some defenders of no platforming concede that content-based speech regulation is problematic in the public sphere but point out that it is normal and even necessary in academic contexts. ${ }^{5}$ Decisions on publication, hiring, and tenure must be grounded in what people have written and said. But no platforming is a specific kind of content-based speech regulation akin to what in legal contexts is called "viewpoint discrimination". One

2 You can read the petition here. https://www.change.org/p/cardiff-university-do-not-host-germaine-greer. It is worth noting that Greer's views on transgender women were not to be the subject of her lecture.

3 Francis Dinkelspiel, "UC Berkeley Spent Close to $\$ 4 \mathrm{M}$ on security in just one month," Berkeleyside, February 6, 2018, https://www.berkeleyside.com/2018/02/06/uc-berkeley-spent-close-4m-security-justone-month-2017.

4 Abena Appa Sampong, et al., "RE Bannon at U Chicago," January 18, 2018, https://docs.google.com/ document/d/11HbJtIJkzMSF5aitP4Cy1YZmQUC1_70EX2or4oUOUdQ/edit. The President and Provost rejected the letter's recommendation. But Bannon and the event organizers could not agree on a date.

5 Robert Simpson and Amia Srinivasan, "No Platforming," in Academic Freedom, ed. Jennifer Lackey (Oxford: Oxford University Press, 2018), 186-209. 
engages in viewpoint discrimination when a particular position on an issue is singled out for regulation while opposing positions on that same issue are not.

Given that the focus here is epistemological, it helps to think of no platforming as conclusion-based. The complaint against Greer, for instance, was not that she speaks about transgender issues or even that she endorses some particular argument on such issues. The petition was grounded in the fact that she endorses a specific conclusion. If someone had been invited to campus to defend the opposite proposition, there would have been no petition (or, if there were, it would have been signed by a different set of people). The same is true in the case of Steve Bannon. Those who attempted to no platform him did not—and presumably would not—object to holding an event where his views are publicly critiqued. To say that there are good epistemic reasons for no platforming on a university campus then is to say that allowing certain propositions to be publicly defended on campus somehow undermines our epistemic goals, regardless of the argument employed and the person employing it. Each of the epistemic justifications for no platforming discussed here highlight a different way in which that is supposed to happen.

\section{The Clearer Perception and Livelier Impression}

The primary epistemic reason to invite speakers to campus is to engage with their arguments and ideas. But, many will think, we stand to gain nothing from engaging with something as stupid as flat Earth theory. In this section, I will apply and expand upon some old and familiar arguments to show that there is more to learn here than you might think.

Chapter 2 of Mill's On Liberty-the locus classicus for a philosophical attack on censorship_-primarily concerns suppression of speech in the public square and not the university campus. Even so, Mill's most important arguments are chiefly epistemic and carry over to the present topic. Mill puts the main argument as a dilemma. On the one hand, it could be that the status quo opinion is false and the dissenting opinion is true. In that case, suppressing and refusing to engage means missing out on an opportunity to correct ourselves. On the other hand, even if the dissenting opinion is false and known to be so, suppressing it robs us of the opportunity to gain, in his words, "the clearer perception and livelier impression of truth produced by its collision with error." 6

Many will be understandably unmoved by the idea that we should engage with flat earthers because maybe we are the ones who have it wrong. The possibility that a flat earther might correct us should not be completely discounted, however. One can be right without being completely right. ${ }^{7}$ For at least some of us, it could be that, while we are undoubtably correct in our belief that Earth is round, we are wrong or ignorant about some important and connected matters in a way that is best revealed by confronting flat Earth arguments. Still, as far as this example goes, the interesting point is on the second horn of the dilemma.

To appreciate how engaging with a flat earther might give us a clearer perception and livelier impression of the truth, consider the following passage from a recent flat Earth manifesto:

A copy of the book "The Lighthouses of the World" and a calculator are enough to prove that the Earth is not a globe, but an extended flat plane. The distance from which various lighthouse lights around the world are visible at sea far exceeds what

John Stuart Mill, On Liberty ed. Michael Mathias (New York: Pearson 2007 [1859]), 77.

Ibid., 103. 
could be found on a globe Earth 25,000 miles in circumference. For example, the Dunkerque Light in southern France at an altitude of 194 feet is visible from 28 miles away. Spherical trigonometry dictates that if the Earth was a globe with the given curvature of 8 inches per mile squared, this light should be hidden 190 feet below the horizon! $!^{12}$

We all know the lighthouse "proof" has a false conclusion. But how many of us can identify exactly where the errors lie? For at least for some of us, a fair amount of reflection and intellectual labor is required. (Is the proof valid? Are the premises true?) By engaging with the lighthouse argument, we stand to acquire new knowledge or, at least, to retrieve some forgotten bits.

More recent work in epistemology provides further grounds to think engaging with a flat earther can intellectually improve us. First, it can advance our understanding. On the kind of view defended by Kvanvig, understanding is a valuable epistemic good and "a cognitive achievement distinct from knowledge." 9 A Jeopardy! champion might memorize, and thereby come to know, a long list of facts concerning, say, organic chemistry. And this might enable her to dominate the category. But mere memorization does not provide the contestant with understanding. On Kvanvig's conception of it, understanding involves possessing "a body of information together with the grasping of explanatory connections concerning that body of information." 10 One who understands not only possesses the facts but appreciates how they hang together.

Engagement with the lighthouse argument is an impetus to achieving understanding in this sense. We know Earth is not flat. But not all of us possess the mathematical knowledge required to calculate the maximum distance from which an object of a given height should be visible from the surface of a sphere. Fewer grasp how things like refraction, tides, and atmospheric conditions affect these calculations in the real world. Appreciating exactly why the lighthouse argument fails requires both knowing these things and bringing them together in a way that many will not have been able to do beforehand (and there is the added benefit of learning a thing or two about the lighthouses of the world).

In response, some may insist that anyone at a university will be sharp enough to immediately spot the flaws in the lighthouse argument. So, for us, there is no payoff to engaging with that argument and certainly no reason to bring someone in to defend it. I suspect anyone with such a high opinion of the level of knowledge and critical thinking skills prevalent in today's universities does not teach Intro (or attend many committee meetings). And we must not forget that NBA legend and erstwhile flat Earth spokesperson Shaquille O'Neal holds a doctorate in education. ${ }^{11}$ But in any case, lighthouse arguments are not all the flat earther has to offer.

12 Lee Mclntyre, "Calling All Physicists" American Journal of Physics 87 (2019): 694-95.

9 Jonathan Kvanvig, The Value of Knowledge and the Pursuit of Understanding (Cambridge: Cambridge University Press, 2003), 188.

10 Ibid., 200.

11 In fairness to Shaq, it should be noted that he eventually said he was joking-after everyone made fun of him. And even if O'Neil was only playing around, Kyle Irving was serious. And he went to Duke. For the full story, see Ben Rohrbach "Unfortunately, Shaquille O'Neal isn't actually a flat-Earther: 'I'm joking, you idiots'," yahoo!sports, March 23 2017, https://sports.yahoo.com/news/shaquille-oneal-isnt-aflat-earther-after-all-im-joking-you-idiots-183258371.html and "Kyrie Irving on Flat Earth Comments: I'm Sorry," NBA.com, https://www.nba.com/news/kyrie-irving-regrets-flat-earth-comments. 
In an editorial published in The American Journal of Physics, Lee Mclntyre calls on physicists to engage with flat earthers. He recounts his experience at the 2018 Flat Earth Society Conference in Denver, Colorado. "You'd be wrong," he says,

to think that all their claims were simple. Some of the thought experiments and experimental puzzles were actually quite hard, not because they were right, but because they were so intricately wrong. As a philosopher of science, rather than a physicist, I was also handicapped by my dim recollection of such topics as the Coriolis effect. ${ }^{12}$

The same reasons offered for thinking that engaging with the lighthouse argument can advance knowledge and understanding apply equally well to more educated people and these more sophisticated sophisms.

There is another, related way engaging with a flat earther can intellectually improve us. Plato's Meno includes a famous discussion of the question of why knowing something is more valuable than just holding the correct opinion on it. The person who correctly guesses that the road to Larissa is to the left, the challenge goes, will get there just as well as the person who knows the way. So why value knowing? Socrates proposes that the value of knowledge lies in the fact that it is "tied down" or "tethered" in a way that mere correct opinion is not.

Duncan Pritchard elaborates. Suppose the road to Larissa is to the left but it loops around in the opposite direction for a while. The person who knows the way, say, because he has seen the map, will be unsurprised and stay the course. The lucky guesser is more likely to question his choice and turn around. ${ }^{13}$ Williamson, who uses a different example to make the same point, says knowledge is less susceptible to "rational undermining by future evidence. ... If your cognitive faculties are in good order, the probability of your believing $p$ tomorrow is greater conditional on your knowing $p$ today than on your believing $p$ truly today." 14

There is a debate about whether a belief's being tied down in this sense is a requirement on knowledge and whether the value of knowledge over mere true belief is best explained in those terms. ${ }^{15}$ But even if it is not a requirement on knowledge or the primary source of the value of knowledge, it is uncontroversial that the kind of stability a true belief enjoys when backed by an understanding of the supporting reasons is epistemically valuable. Engagement with contrary opinions can make our beliefs more stable in that sense. This point was not lost on Mill either. Socratic dialogue and debate, even over propositions we already rightly accept, puts us a position "to attain a stable belief resting on a clear apprehension both of the meaning of the doctrines and their evidence." ${ }^{16}$ No platformers worry that engaging with flat Earth arguments will undermine knowledge and encourage an irrational form of skepticism (more on that later). But confronting such arguments from the controlled and comfortable environment of the university auditorium - and in the presence of bona fide experts poised to critique

12 Lee McIntyre, "Calling All Physicists" American Journal of Physics 87 (2019): 694-95.

13 Duncan Pritchard, "Recent Work on Epistemic Value," American Philosophical Quarterly 44, no. 2 (2007): 85-110, 86.

14 Timothy Williamson, Knowledge and Its Limits (Oxford: Oxford University Press, 2000), 79.

15 For a criticism of the Pritchard-Williamson line, see Michael Veber, Tell Me Something I Don't Know: Dialogues in Epistemology (Peterborough, ON: Broadview Press, 2018), 20-22.

16 Mill, On Liberty, 101. 
them-can also make one better equipped to spot the errors in similar arguments confronted out there on the mean streets of the internet.

No platformers might concede that we can learn from flat Earth arguments but still insist that no one should be invited to defend them on campus. If there is value to knowing where and why flat Earth arguments fail, why not just have a good prof lay it all out for us? Of course, one could ask that about any prospective guest speaker. Why bring somebody in when you could just have one of our own resident experts read the paper to us and, where necessary, tell us where it goes wrong? As Mill saw it, the point of allowing contrary points of view to be publicly defended is to bring the ideas into "real contact" with our minds. It is not enough to that we "hear the arguments of adversaries from his own teachers, presented as they state them, accompanied by what they offer as refutations;" we must hear them from "people who actually believe them, who defend them in earnest and do their very utmost for them."17

Mill was correct to think there is a unique benefit to engaging with those who advocate contrary opinions but incorrect to think the advocates must be sincere. When all earnest believers are booked, a good actor can fill in. William Lycan once spent an entire semester pretending to be a mind-body dualist and defending the view "as energetically as [he] could" 18 in a seminar. Nearly every contemporary philosopher of mind-including Lycan-thinks substance dualism has no real chance of being correct. That fact gave Lycan "methodological" ${ }^{19}$ reason to publicly defend it with gusto for four straight months. A ruse like this serves to bring not only the minds of the audience members but also of the actor into real contact with the contrary position. In Lycan's case, the experiment advanced his own views and spawned new research. In the same way, bringing a flat earther (or someone pretending to be one) to campus will make it harder to simply ignore and dismiss his position. You might have to think about it.

The knee-jerk reaction to inviting a flat Earther to campus says we stand little or nothing to gain from hearing someone defend something so stupid. The Millian argument above is not a decisive demonstration that we would epistemically benefit from hosting a flat Earther on campus. But it is enough to demonstrate that the mere fact that flat Earth theory is extremely stupid does not constitute a strong epistemic reason for no platforming.

\section{Following the Argument Where It Leads}

Rather than deny there is any epistemic gain, a different type of argument for no platforming focuses on the costs. All arguments for flat Earth theory have false conclusions and thus are, by definition, misleading. By allowing a flat Earther to defend his stupid theory on campus, we run the risk that he will succeed in changing people's minds. There are two ways to understand the threat here. On what we can call a "first-person" understanding, the worry is that exposure to flat Earth arguments will end up changing my mind. If I take the arguments seriously, I may either end up a flat earther myself or I may become more skeptical in my beliefs about Earth's shape than I should be. And this a reason to refuse to engage with those arguments and limit my exposure to them. On a "third-person" understanding, we have epistemic reason to no platform the flat Earther because he might mislead someone else. The third-person approach will be

17 Ibid., 95.

18 William G. Lycan, On Evidence in Philosophy (Oxford: Oxford University Press, 2019 ), 66 fn8.

19 Ibid., 66. 
discussed in the next section. In this section, I shall argue that refusing to engage with the arguments of a flat Earther on the grounds that he might change my mind violates the epistemic ideal of following the argument where it leads.

Thomas Kelly notes how a number of thinkers throughout the history of Western philosophy, starting with Socrates and continuing through Mill and Russell, have taken the practice of following the argument where it leads as the guiding principle of all good inquiry. ${ }^{20}$ To follow the argument where it leads is also said to define the very purpose of the university. That claim gets asserted not only in university faculty manuals ${ }^{21}$ but also in the US Supreme Court. The 1957 landmark free speech and academic freedom case of Sweezy $v$. New Hampshire concerned an economist who was charged with a crime for refusing to answer various questions from the state Attorney General about the content of a university lecture including whether he had ever espoused the theory of dialectical materialism. The Court found in favor of Sweezy. In his concurring opinion, Justice Frankfurter quotes and endorses a statement from the Chancellors of the Universities of Cape Town and Witwatersrand. "A university is characterized by the spirit of free inquiry, its ideal being the ideal of Socrates_-'to follow the argument where it leads." 22 But what does it mean to follow the argument where it leads? And why think it is an epistemic virtue?

On the most minimal understanding of it, following the argument where it leads opposes dogmatism. Kelly develops the idea further. On the account he defends, following the argument where it leads with respect to $p$ requires whatever attitude you have toward $p$-belief, disbelief, or suspension of judgment-to be reasonable given your total evidence. But, while holding a reasonable attitude is necessary for following the argument where it leads, it is not sufficient. An inquirer who reasonably believes that $p$ can still be "dogmatically committed" 23 to that belief. A subject is dogmatically committed to his belief that $p$ whenever he possesses a disposition to maintain that belief in the face of evidence that makes it reasonable for him to abandon it. To adapt an example from Nozick, ${ }^{24}$ someone might reasonably believe her grandson is safely playing in the yard because she sees him through the window. But suppose also that Grandma's desire for the continued safety of her loved one runs so deep she would believe her grandson is safe even if her evidence strongly suggested otherwise. In that case, Grandma has both a reasonable belief and a dogmatic commitment to that belief. One can also harbor a "dogmatic aversion" 25 to believing something. A subject who disbelieves or suspends judgment on $p$ might be disposed not to believe that $p$ even if his evidence makes belief rational. Following the argument where it leads is incompatible with dogmatic commitments and dogmatic aversions.

To follow the argument where it leads on this account is to exhibit a kind of "modalized reasonableness." ${ }^{26}$ It is a disposition to believe, disbelieve, or suspend judgment on any proposition whatever in response to it becoming reasonable to do so. Kelly's account explains why following the argument where it leads is plausibly viewed as an epistemic

20 Thomas Kelly, "Following the Argument Where it Leads," Philosophical Studies 154 (2011): 105-24. Kelly also discusses these issues in Chapter 9 of his forthcoming book Bias: A Philosophical Study.

21 Ibid., 106, 120.

22 Quoted in Rodney Smolla, The Constitution Goes to College (New York: New York University Press, 2011), 31.

23 Kelly, "Following the Argument Where it Leads," 109.

24 Robert Nozick, Philosophical Explanations (Cambridge, MA: Harvard University Press, 1981), 179.

25 Kelly, "Following the Argument Where it Leads," 110.

26 Ibid., 113. 
virtue and a fundamental norm of inquiry. To follow the argument where it leads is to follow your total evidence where it leads. Provided our reasoning and sources of evidence are generally reliable, this will get us to the truth most of the time. That is a tautology. Dogmatic commitments and aversions are, by definition, indifferent to the evidence. And that is why the Socratic injunction commands us to overcome them. This also explains why following the argument where it leads is so commonly taken to encapsulate the academic mission of the university.

While there is much to be said in favor of Kelly's view, it also leaves something out. And this is particularly important to the present discussion. Paradigmatically dogmatic people can meet Kelly's criteria for following the argument where it leads. Consider an adherent of what C.S. Peirce called "the method of tenacity". Such a subject maintains belief by "systematically keeping out of view all that might cause a change in his opinions." ${ }^{27}$ Practitioners of this brand of "ostrich" 28 epistemology might hold beliefs that are warranted given their total evidence. And they may also have a healthy disposition to abandon those beliefs if the acquisition of new evidence makes it reasonable for them to do so. But, as long as their efforts to avoid confrontation with counterevidence succeed, that disposition is never activated. And they never change their minds.

To put the point another way, the most successful kind of dogmatist does not operate by simply digging in and maintaining his current attitudes come what may. That can be hard for even the most devoted of us to pull off in the long run. Despite the conviction and mountains of evidence, Ted Bundy's mother insisted her boy was innocent. But even she gave up after he confessed in the hours just before his execution. "Experience," as William James says, "has a way of boiling over." ${ }^{29}$ The prudent dogmatist does not try to keep a lid on it but takes the pot off the burner. Dogmatism works best as a resolution made in advance. And it is, as Kripke points out, primarily a resolution "to avoid certain types of contact with alleged evidence, such as reading the wrong books (for they can contain nothing but sophistry and illusion), associating with the wrong people, and so on." ${ }^{30}$ But again, a person who does that may still hold a reasonable belief and be disposed to give it up if that is what his evidence recommends.

The problem can be fixed by amending Kelly's account. In addition to being reasonable in holding whatever attitude one does on $p$ and not being dogmatically committed to that attitude or dogmatically averse to adopting a different attitude, a subject committed to following the argument where it leads is also not dogmatically averse to considering evidence in the first place. By saying that a subject is dogmatically averse to considering evidence, I mean that he is averse for a particular kind of reason. Sometimes we avoid looking into things out of laziness, lack of interest or lack of time. ${ }^{31}$ That is not dogmatic aversion. When someone is dogmatically averse to considering evidence

27 Charles Sanders Peirce, "The Fixation of Belief," Popular Science Monthly 12 (1877): 1-15, 6.

28 Ibid., 6.

29 William James, "The Meaning of Truth," in The Writings of William James: A Comprehensive Edition, ed. John J. McDermott (Chicago: University of Chicago Press, 1977 [1907]), 312.

30 Saul Kripke, Philosophical Troubles: Collected Papers, Vol. 1 (Oxford: Oxford University Press, 2011), 49.

31 In a 2008 interview, Jerry Fodor says people think they want to know things but, really, "if you ask-how much would you pay to know, the answer is not much. Do you care how your refrigerator works? No, as long as there's a repairman around when it breaks down. Nobody really cares." Much of my own experience as an educator and homeowner confirms this. For the full interview, see Suzan Mazur, "Jerry Fodor Held High Ground to Evolution's Militant Fundamentalists," The Huffington Post, December 23, 2017, https://www.huffpost.com/entry/jerry-fodor-held-high-ground-to-evolutionsmilitant_b_5a3ec86ae4b0d86c803c722f. 
or arguments concerning $p$, it is because doing so may result in him changing his mind about $p$.

Refusing to confront flat Earth arguments because those arguments might change my mind violates the epistemic ideal of following the argument where it leads. The underlying logic is exactly that of the ostrich epistemologist as described by Peirce.

I remember once being entreated not to read a certain newspaper lest it might change my opinion upon free-trade. 'Lest I might be entrapped by its fallacies and misstatements,' was the form of expression. 'You are not,' my friend said, 'a special student of political economy. You might, therefore, easily be deceived by fallacious arguments upon the subject. You might, then, if you read this paper, be led to believe in protection. But you admit that free-trade is the true doctrine; and you do not wish to believe what is not true. ${ }^{32}$

Just swap talk of reading a newspaper with listening to a lecture, 'free-trade' with 'round Earth', 'political economy' with 'astronomy', 'protection' with 'flat Earth', and 'not true' with 'stupid'. And then run through the passage again.

In response, a critic may either reject the idea that following the argument where it leads is a norm of inquiry or contend that cases like flat Earth are an exception to the rule. It is not hard to see why one might be attracted to that view. Some flat Earth arguments are, as Mclntyre put it, so intricately wrong that even well-educated people can have a hard time identifying why they fail. But since we know flat Earth theory is false, we know all such arguments are misleading. So why risk it? Another remark from Kripke is helpful here. "Sometimes the dogmatic strategy is a rational one. I myself have not read much defending astrology, necromancy and the like. ... Even when confronted with specific alleged evidence, I have sometimes ignored it although I did not know how to refute it." 33

It is worth noting that Kripke may be underselling himself. It is hard to buy the idea that the man who, by some accounts, single-handedly reversed the linguistic turn and convinced an entire generation of philosophers to take metaphysics seriously again is incapable of producing any good argument against the proposition that people can predict the stock market by observing the stars or communicating with the dead. ${ }^{34}$ But even so, what about us mortals? We might not be able to refute clever arguments for necromancy, astrology, and, we can add, flat Earth theory. Does that give us a strong reason to avoid confronting those arguments? And is it a strong reason to keep them off our campus?

No. The risk here is greatly exaggerated. Anyone flummoxed by an argument for astrology or necromancy can often gather compelling counterevidence in a few seconds by pulling out a smart phone. As Cassam reminds us, "the internet enables the propagation of crackpot theories [but] it also supplies the resources required to rebut them." ${ }^{35}$ Refutations of some flat Earth arguments-including, for any cheaters out there, the lighthouse argument-are also easily obtainable. Of course, as Mclntyre reminds us, that will not always be the case. But following the argument where it leads does not require changing your mind whenever you run across an argument you do not know how to refute.

32 Peirce, "The Fixation of Belief," 6.

33 Kripke, Philosophical Troubles, 48.

34 Here I paraphrase Quassim Cassam, Vices of the Mind: From the Intellectual to the Political (Oxford: Oxford University Press, 2019), 117 fn15.

35 Ibid., 120. 
To see why, consider the epistemic position of the sort of person Kelly calls "the Average Eleatic" ${ }^{36}$-an unsophisticated inhabitant of the ancient world-who confronts one of Zeno's famous arguments against motion and is unable to provide any compelling account of exactly why or where it fails. The Average Eleatic will still possess overwhelming empirical evidence that stuff moves. Since following the argument where it leads is following one's total evidence where it leads, the Average Eleatic is not guilty of dogmatism by continuing to believe in the existence of motion despite not knowing how to refute Zeno's argument. The Average Eleatic should, however, walk away with a newfound skepticism about Zeno's premises. Assuming he knows the argument is valid, he knows that at least one of those premises, which before had struck him as obviously true, is false. This is an advancement in his overall understanding of the universe. And that again underlines the epistemic value of engaging with arguments for stupid conclusions.

In other words, following the argument where it leads does not mean following some particular argument where it leads. Rare is the case where one's total evidence concerning a proposition is captured by a single argument. It is irrational for you to follow some particular argument where it leads when you have better evidence leading in the other direction. 'The argument' in the Socratic slogan is synecdoche.

It is clear how Kelly's point about the Average Eleatic carries over. It is rational for Kripke to believe that astrology and necromancy are bunk despite being unable to refute arguments to the contrary but that is not a counterexample to the claim that it is rational to follow the argument where it leads. Kripke, just like the rest of us, has plenty of good reason to reject those things. (And if he does not, he can-and should-go get himself some.) If the argument of the astrologer or necromancer is clearly valid, that means Kripke has gained a reason to doubt the premises. Likewise, the fact that Mclntyre continues to believe Earth is round despite being unable to explain exactly where the most clever and complicated flat Earth arguments fail does not mean he is dogmatically refusing to follow the argument where it leads. His total evidence still justifies rejecting flat Earth theory. Open-mindedly confronting and engaging with arguments for stupid conclusions is not as risky as the ostrich thinks. ${ }^{37}$ And you can learn from it.

\section{Epistemic Paternalism}

The possibility that a flat earther might change my mind is not a good reason for me to no platform him rather than just follow the argument where it leads. But it is doubtful any no platformers are thinking in first-person terms. I am confident no one who signed the petitions against Bannon or Greer did it because they thought they might end up convinced. Likewise, it is unlikely that anyone inclined to no platform flat Earth theory would think they are at risk of being taken in. It's other people we have to worry about. And there is certainly a chance the flat earther will convince someone if we allow him

36 Kelly, "Following the Argument where it Leads," 114

37 Jeremy Fantl defines open-mindedness as an attitude taken toward particular arguments. On his view, you treat an argument open-mindedly only if you are willing to change your mind in response to that argument when you cannot identify the flaw. Fantl argues that open-mindedness is not always an epistemic virtue. In keeping with the points made above, I reject Fantl's definition of 'open-mindedness' and instead view it as another name for the epistemic ideal of following the argument-i.e., your total evidence-where it leads. For a defense of Fantl's view, see his book The Limitations of the Open Mind (Oxford: Oxford University Press, 2018). 
to air his views on campus. The question, however, is whether that constitutes a strong epistemic reason to no platform. In this section, I will argue that it does not.

The third-person argument for no platforming commits us to epistemic paternalism. Paternalism in general is the practice of interfering with people without their consent on the grounds that those interfered with will be better off. Epistemic paternalism is the practice of interfering with people's efforts at inquiry without their consent on the grounds that they will be epistemically better off. Insofar as it is an effort to restrict people's access to flat Earth arguments for their own epistemic good and without consulting them, no platforming is epistemically paternalistic.

To appreciate why this presents a problem, it helps to draw an analogy from controversies surrounding paternalism in non-epistemic contexts. Consider paternalistic justifications for prohibiting steroids in sport. An FDA anti-steroids poster from 1987 bears the slogan "Don't Pump Trouble" and features a picture of Jesse "The Body" Ventura with a line that reads, "Using steroids isn't worth the risk. I've tried them and I've seen the harm they can do." ${ }^{38}$ There are two problems with The Body's position. First, there is the empirical question of whether steroids, if used correctly (assuming there is such a thing), are really all that risky. And second, there is a philosophical question of values. Steroid use in sport is often criticized on the grounds that it manifests the objectionable attitude that winning is more important than anything, including one's own long-term health. But, as W.M. Brown points out, for some athletes, "winning is more important." 39 To prohibit people from using steroids on the grounds that it is not worth the risk is to impose a certain optional prioritization of values upon them without their consent. This is the core reason why so many regard paternalistic interference as an affront to personal sovereignty.

The epistemically paternalistic justification for no platforming flat earthers faces the same kinds of difficulties. Although he does not discuss no platforming, Kristoffer Ahlstrom-Vij defends epistemic paternalism in other contexts. ${ }^{40}$ According to him, there are cases where we can rationally predict that interfering with people's inquiry will maximize their true beliefs and minimize their false ones. But it has not been shown that prohibiting flat earthers from defending their views on university campuses will have this effect. As argued earlier, engaging with a flat earther might generate more true beliefs in people and it might make the ones they already have more stable. There are also easy ways to ease the epistemic risks. For instance, rather than let the flat earther have the entire hour, why not follow the Chicago format and assign a credible expert to offer objections and criticism? And there is still the second kind of problem for paternalism in this case. Just as differences in value may make steroid use worth it to some but not others, there are different epistemic values that different people will prioritize differently. This does not mean epistemic paternalism is never justifiable. But it does make it hard to say whether no platforming the flat earther will make people epistemically better off and makes the effort to do so intrinsically problematic.

To see why, let us look further at Ahlstrom-Vij's defense of epistemic paternalism. Following the lead of Goldman's seminal discussion of epistemic paternalism, ${ }^{41}$ Ahlstrom-Vij proceeds from the assumption that "formation of true belief and avoidance of

38 The poster can be seen here: https://collections.nlm.nih.gov/catalog/nIm:nlmuid-101437736-img.

39 W.M. Brown, "Paternalism, Drugs, and the Nature of Sports," Journal of the Philosophy of Sport 11 (1984): 14-22.

40 Kristoffer Ahlstrom-Vij, Epistemic Paternalism: A Defense (New York: Palgrave Macmillan, 2013).

41 Alvin Goldman, "Epistemic Paternalism: Communication Control in Law and Society," Journal of Philosophy 88 (1991): 113-11. 
false belief" are the "paradigm goals of epistemic practices." ${ }^{42}$ But there are, as William James pointed out, different ways to prioritize those twin goals. ${ }^{43}$ And that can affect our epistemically motivated decisions. The more weight one gives to not believing something false, the more it makes sense to hold out until there is a great deal of evidence that $p$ is true before taking up the belief. On the other hand, the more one values not missing out on believing the truth, the more it makes sense to adopt lower standards. ${ }^{44}$ Differences of this sort can also affect judgments about whether one is better or worse off engaging with the arguments of contrarians. The more you value avoiding error, the more dangerous it is to believe and thus the more open you might be to entertaining arguments from those out to refute you. But if you value true belief above all else (and you are fully convinced you have it), it makes more sense to avoid arguments that might change your mind.

The problem is exacerbated by the fact that obtaining truth and avoiding error are neither our only epistemic goals nor the only ones with a claim to being paradigmatic. Knowledge and understanding, for instance, are also both paradigmatic goals of inquiry ${ }^{45}$ and, as noted above, there are numerous ways engaging with a flat earther can advance them. And beyond truth, knowledge, and understanding, there are other epistemic goods that should be factored in when deciding whether an action makes someone else epistemically better off. For instance, even if it is not a requirement on knowledge, the ability to refute counterarguments is a highly prized epistemic commodity-especially among philosophers-and one that is potentially compromised by no platforming.

Given all of that, it is hard to justify a prohibition against defending flat Earth theory on campus on the grounds that it will make those affected by the prohibition epistemically better off. And it is reasonable to assume the burden is on the no platformer since they are the ones doing the interfering-both with those who might want to hear a flat earther defend his view and with those who might want to bring him in for that purpose. Furthermore, as argued in the previous section, a willingness to engage with flat Earth arguments flows naturally from a commitment to following the argument where it leads. The no platformer is effectively deciding for other people that they ought not follow the argument where it leads in this case. But following the argument where it leads, we are often told, is the defining purpose of any university. The default position should therefore be that those who want to engage with flat theory on campus can unless there is a very strong reason not to. And as of now, there is not. But we will keep looking.

\section{Higher-Order Evidence}

Neil Levy offers a defense of no platforming explicitly designed to avoid accusations of paternalism. In keeping with the points made above, Levy says paternalistic justifications of no platforming bring their proponents "uncomfortably close to agreeing that they infantilize the audience. To treat others paternalistically is, after all, to treat them as lacking

42 Ahlstrom-Vij, Epistemic Paternalism, 40.

43 William James, The Will to Believe and other Philosophical Essays (Cambridge, MA: Harvard University Press. 1979 [1897]).

44 Thomas Kelly makes this argument in "Evidence can be Permissive," in Contemporary Debates in Epistemology, 2nd edition, ed. Mathias Steup (Chichester UK: Wiley Blackwell, 2014), 298-312, 301.

45 Duncan Pritchard, "Epistemic Paternalism and Epistemic Value," Philosophical Inquiries 1 (2013): 10-37. 
(in certain respects) the capacity rationally to make their minds up for themselves." ${ }^{46}$ But, just as some have argued that respect for human autonomy requires that we maintain the ban on steroids in sport, ${ }^{47}$ Levy argues that respect for intellectual autonomy provides a "strong" 48 and "powerful" ${ }^{49}$ reason in favor of no platforming (albeit one that "may perhaps sometimes be defeated" ${ }^{50}$ ).

According to Levy, by hosting "bad speech" 51 on campus, we thereby create a certain kind of misleading higher-order evidence and respect for the intellectual autonomy of others gives us strong reason to refuse to do that. First-order evidence is evidence bearing directly on whether $p$. The lighthouse argument for flat Earth (and rebuttals of it), for instance, are located at this epistemic level. Higher-order evidence is evidence bearing "on the reliability of the relationship" between the first-order evidence and $p$ or "the reliability of the agent who is assessing that relationship." ${ }^{2}$ The credentials (if there are any) of Eric Dubay, author of the flat Earth manifesto quoted earlier, provide higher-order evidence relevant to the status of the lighthouse argument. On Levy's view, the very fact that someone is invited to speak at a university constitutes higher-order evidence that the view being defended is "worth taking seriously" 53 and that the person defending it is "worthy of a respectful hearing" because "the inviters consider the speaker sufficiently expert, or sufficiently representative of expertise to have an opinion on that topic that should be taken into consideration." ${ }^{54}$ No platforming is therefore justifiable on epistemic grounds for the same reason refraining from lying is. In both cases, we refuse to produce misleading evidence out of "respect for people's intellectual capacities and autonomous reasoning." 55 Hosting a flat earther on campus is akin to asserting that he is a well-credentialed expert and this entails that there is significant expert disagreement about the Earth's shape. It is therefore deceptive on our part to offer the invitation and doing so will undermine people's intellectual autonomy. To add further support to the argument, Levy goes on to say that the misleading higher-order evidence conferred by an invitation to speak on a university campus is much harder to overturn or rebut than any misleading first-order evidence presented by the speaker at the event. The latter can be dispatched by assigning a panel of critics to dispute what the speaker says or by allowing objections from the floor. But provision of a reputable platform "just does confer credibility on you, no matter what anyone says."

It should be granted that hosting a speaker on a university campus will normally confer some amount of credibility on that person. But calling this a strong and powerful epistemic reason in favor of no platforming both overestimates the amount of credibility

46 Neil Levy, "No-Platforming and Higher-Order Evidence, or Anti-Anti-No-Platforming," Journal of the American Philosophical Association 5 (2019): 487-502, 491. Levy also points out that the psychological research needed to support the claim that epistemic paternalism would have the desired effect is controversial.

For a critique of that kind of argument against steroid use in sport, see Michael Veber, "The Coercion Argument Against Performance-Enhancing Drugs," Journal of the Philosophy of Sport 41 (2014): 267-277.

48 Levy, "No-Platforming and Higher-Order Evidence," 487.

49 Ibid., 500.

50 lbid., 487.

51 Ibid., 487.

52 Ibid., 491.

53 lbid., 487

54 lbid., 495-96.

55 Ibid., 491.

56 Ibid., 499. 
conferred and underestimates the ways in which this kind of higher-order evidence can be defeated. In 2002, Gene Ray, the self-proclaimed wisest man on Earth, was invited to MIT to defend his all-encompassing theory of the universe: The Time Cube. ${ }^{57}$ Those familiar with the story will know that Ray was invited to MIT by a student organization as some sort of college prank. While pranks of that order are rare (epic in fact), it is common for people to be invited to speak at universities for reasons that have nothing to do with their intellectual credibility. Whether events are deemed "successful" by the parties who provide the funding is typically a function of whether the room fills. Inviting an athlete, journalist, political pundit, or celebrity over a well-respected scholar is usually a far better way to achieve success in that sense. ${ }^{58}$ While inviting a flat earther might send an "epistemic signal" 59 that this person is a respected and accomplished intellectual, the signal is weaker and more ambiguous than no platformers would like us to think. Furthermore, as Mclntyre points out, flat earthers regularly use the fact that they are shut out from debate and discussion with real scientists as "the ultimate sign [they] are right." ${ }^{60}$ So if we choose to no platform them, that too will send a favorable signal-at least to some.

In response, it may be insisted that the signal sent by providing the platform is much stronger than the one sent by refusing it and, as Levy says, the credibility the former confers is permanent. But this claim is also dubious. It is true that you cannot change the past but, if we invite a flat earther to speak on a university campus, we are not so much asserting that he is credible as we are implicating it. And the implication is easily cancelled. If we are worried that, by hosting a flat earther on campus, we are generating misleading evidence that he is an expert scientist, we can correct for that by making our Millian motivations clear to the public and, with the use of the internet, the world. If we wish, we can also remind everyone that, although there is much potential epistemic gain in engaging with flat Earth theory, pretty much everyone knows it is false and has for millennia. And it may be that we need not say anything. If you did not know the whole story, you might think the fact that Gene Ray spoke at MIT gives him and his theory permanent credibility. But once you google 'Time Cube Theory', his credibility drops to zero.

It is also worth noting that generating misleading evidence-be it first- or higher-order-can be good and even necessary for the advancement of our epistemic aims. Even if it is true that hosting a flat earther is deceptive, that fact does not by itself constitute a strong epistemic reason against doing it. Lycan's ruse made metaphysical dualism harder both for him and his audience to ignore and dismiss. That was the whole point. The fact that it was deceptive served in this case as an epistemic reason in favor of doing it. To take another example, Williamson recounts how he once lied to a room full of people during a public talk. ${ }^{61} \mathrm{He}$ asserted the falsehood that he has given exactly one Power Point presentation and it was a disaster so they would infer the truth that he has never given a successful Power Point presentation. This created an auditorium full of real-life Gettier cases and was crucial to the point he was trying to prove. So even if it

57 An overview of Time Cube Theory, with a helpful diagram, is available on Wikipedia. https://en.wikipedia. org/wiki/Time_Cube.

58 My own university once invited Tomi Lahren to speak on campus. Judging by the write-up in the local news, the event was extremely successful. For more, see "Full House for controversial speaker at ECU," WITN, March 23, 2017, https://www.witn.com/content/news/ECU-student-group-responding-to-backlash-overupcoming-speaker-416903793.html.

59 Levy, "No-platforming and Higher-Order Evidence," 496.

60 Mclntyre, "Calling All Physicists," 694.

61 Timothy Williamson, The Philosophy of Philosophy (New York: Blackwell, 2007), 192. 
is a little deceptive for a university to host a flat earther on campus, it might be worth it if it makes people think.

My final objection to the argument from higher-order evidence concerns the nature of the misleading evidence in question. Levy claims that hosting bad speakers on campus conveys the higher-order falsehood that their opinions are "worth taking seriously." ${ }^{2}$ But, as argued above, there are plenty of reasons to think engaging with arguments for flat Earth theory can advance your epistemic aims. In that sense, those arguments are worth taking seriously and therefore the evidence generated by the invitation is not misleading. Furthermore, no platforming a flat earther on the assumption that his position is not "worth taking seriously" is akin to restricting steroids on the grounds that they are not "worth the risk". Whether doing either is worth it to me is a function of my own goals and priorities. Your results may vary. In any case, it would appear Levy's defense of no platforming is not as un-paternalistic as he thinks.

\section{Academic Freedom}

Opponents of no platforming on campus often contend the practice conflicts with academic freedom. Just as Levy attempts to reverse the argument on those who complain it violates intellectual autonomy, Robert Mark Simpson and Amia Srinivasan have argued that no platforming is not in conflict with academic freedom but can be defended as an exercise of it. In this section, I argue that appeal to academic freedom does not provide good epistemic grounds for no platforming the flat Earther.

Opposition to no platforming is often justified by appeal to a general societal commitment to freedom of expression. Liberal societies typically oppose content-based speech restrictions and tolerate them only in special circumstances. Thus, it might be said, liberal societies should also oppose content-based speech restriction on university campuses. Simpson and Srinivasan object to that line on the grounds that it "treats the university as if it were just an outlet in the marketplace of ideas or an extension of the public square" and that is a mischaracterization because "universities are specialized technical institutions that exist for purposes of teaching and research." ${ }^{3}$ Inspired by the work of Robert Post, ${ }^{64}$ Simpson and Srinivasan offer an account of academic freedom according to which it is not derivative of the general right to free speech that everyone in a liberal society enjoys. Instead, it is a sui generis right specifically crafted to ensure that academics can conduct their work without interference from "outside actors." 65 The clearest violations of academic freedom are cases where administrators, governments, donors, the public or anyone else who is not a member of a given academic discipline attempts to regulate academic speech within that discipline. For instance, if an expert economist expounds economic theories that cause public outcry and one of these outside agents attempts to punish him for it, say, by seeing that he is denied a job appointment or prevented from publishing, the economist's academic freedom is clearly violated. But at the same time, and contrary to what some campus free speech advocates

62 Levy, "No-Platforming and Higher-Order Evidence," 499.

63 Simpson and Srinivasan, "No Platforming," 196. Simpson defends this view further in a later paper. See Robert Mark Simpson, "The Relation between Academic Freedom and Free Speech," Ethics 130 (2020): 287-319.

64 See Robert Post, Democracy, Expertise, Academic Freedom: A First Amendment Jurisprudence for the Modern State (New Haven, CT: Yale University Press, 2013).

65 Simpson and Srinivasan, "No Platforming," 197. 
seem to think, academic freedom does not guarantee anyone, even the experts, the right to a "wide-open discussion of ideas." ${ }^{6}$ If our economist is refused tenure or publication in a journal because others in his field have determined his research does not meet disciplinary standards, that is not an infringement upon his academic freedom but rather a manifestation of theirs. The same is true if our economist is denied a position because, in the judgement of his peers, his teaching falls short of disciplinary norms and standards.

Simpson and Srinivasan apply this account of academic freedom to no platforming in the following way. Since "effective teaching and research requires that communicative privileges be given to some and not others, based on people's disciplinary competence," experts are licensed to act as "disciplinary gatekeepers" who are legitimately empowered to refuse to allow "cranks and shills" to have their views heard and considered in academic settings. ${ }^{67}$ Flat earthers, holocaust deniers, and climate change skeptics "make a joke of the intellectual standards to which teaching and research in these disciplines aspire."68 And since the very purpose of academic freedom is to enable disciplinary practitioners to promote and protect their own intellectual standards, no platforming is a justifiable exercise of that freedom.

There are three ways to interpret the argument here. On the weakest reading, the claim is only that no platforming is "permissible"69 or "compatible with"70 a liberal conception of academic freedom. But the fact that academic freedom permits certain content-based speech restrictions does not entail that it permits the kind of conclusion-based speech restriction we find in no platforming. Moreover, from the fact that something is permissible, it does not follow that there is a good reason to do it. Even if academic freedom is generally valuable for epistemic reasons, not every activity compatible with or permitted by it advances our epistemic aims. The central question in this investigation is not whether no platforming the flat earther is permissible but whether there are strong epistemic reasons to think it is a good idea.

On another reading, the argument says that academic freedom not only permits but requires no platforming. The very existence of academic expertise depends upon there being "an intellectual culture that properly recognizes and esteems the authority of its disciplinary experts" ${ }^{\prime 1}$ and that entails certain points of view must be excluded from debate and discussion. ${ }^{72}$ Academic freedom protects the right of researchers and teachers to pursue their disciplinary aims "free from undue external interference" 73 and what counts as external to a discipline is at least partly determined by the discipline's "axiomatic commitments." 74 Anyone who challenges an axiom is thereby not a member of the discipline that axiom defines. This goes for empirical claims in sciences like astronomy - where the roundness of the planets is axiomatic in this sense if anything is-as well as moral claims in fields in the humanities. "Anyone who wanted to argue against the moral permissibility of homosexuality," Simpson and Srinivasan claim, "would

66 Ibid., 197.

67 Ibid., 198.

68 Ibid., 200.

69 Ibid., 187.

70 Ibid., 195.

1 Ibid., 198.

72 This is how Levy reads Simpson and Srinivasan's argument. Levy, "No-platforming and Higher-Order Evidence," 490.

73 Simpson and Srinivasan, "No Platforming," 207.

74 Ibid., 205. 
be setting themselves outside the axioms that define the field of gender studies." 75 If this is correct, then all academic disciplines must engage in no platforming of some sort because the discipline is in a sense defined by the views its practitioners refuse to consider. ${ }^{76}$

I have two objections to this version of the argument. First, this account of the connection between a discipline and its axioms is dubious. Although there is such a thing as what Kuhn called "normal science"-where the fundamental assumptions of the paradigm go unquestioned-revolutionary science is still science. ${ }^{77}$ Einstein was, after all, a physicist. As a description of how academic disciplines normally operate, it may be correct to say that its practitioners are often effectively prohibited from questioning certain fundamental assumptions. But it does not follow that things must or should always work that way. Adam Becker recounts how the development of quantum mechanics was held back because those who raised certain legitimate foundational questions and challenges to the Copenhagen interpretation were told they were not doing physics. ${ }^{78}$ It is not enough that a discipline has axioms; they must be well grounded in evidence. It is certainly a bad thing if the axioms of the discipline are accepted for bad reasons. And if they are, what better way to correct the problem than to question those axioms? And who better to do that than the disciplinary experts? So why not allow or even encourage it from time to time?

Second, while Eric Dubay should not be hired to teach astronomy at a university and his flat Earth screeds should not be published in any academic journal, it does not follow that flat Earth theory must be no platformed. Suppose that, after reading Mill's On Liberty or McIntyre's editorial, the Department of Astronomy decides to welcome some outsider challenges to its fundamental axioms and invites a flat earther in for a debate. If academic freedom means that "faculty should be autonomous in deciding how on-campus teaching and research events are run," 79 then no outside actors are in any position to stop them. This point is particularly important because the no platformer usually shows up after people have expressed an interest in hosting a speaker or, as in the case of Bannon and Greer, after the invitation has been sent and accepted. Attempting to rile up the public or the university administration with petitions and open letters is the no platformer's signature move. In that sense, no platforming is not a protection of faculty autonomy but an assault on it.

Between the strong and weak readings of the argument from academic freedom lies a moderate view. On this way of understanding things, academic freedom neither merely permits nor entails a prohibition of the defense of stupid ideas on campus. The thought is rather that protection of the integrity of an academic discipline and the intellectual authority of its relevant experts provides a strong-albeit defeasible-reason to prohibit certain stupid ideas from being publicly defended on campus.

It is true that people should not be forced to host the defense of a stupid proposition on campus especially if those people have made it clear they do not want to hear it. But the fact that no one should stop the experts from no platforming a flat earther does not mean they have a strong reason to no platform him. As argued above, there is an epistemic

75 Ibid., 205.

76 Simpson and Srinivasan make an exception in the case of philosophy where, it would seem, no theory is ignored for being too stupid.

77 Thomas Kuhn, The Structure of Scientific Revolutions (Chicago: University of Chicago Press, 1962).

78 Adam Becker, What is Real? The Unfinished Quest for the Meaning of Quantum Physics (New York: Basic Books. 2018).

79 Simpson, "The Relation between Academic Freedom and Free Speech," 317. 
upside to engaging with arguments for stupid ideas. The question here is whether, despite the potential benefits, protection of disciplinary expertise and authority provides a strong basis for no platforming stupid ideas.

The strength of the reason in this case is directly proportional to the likelihood that permitting the defense of a stupid idea on campus will undermine disciplinary expertise and authority. Permitting a flat earther to speak on campus will not destroy the field of astronomy or any other academic discipline. Science is not that fragile. But, if "the intellectual and disciplinary culture of a university is shaped by all of the public speaking activities that happen within the institution," ${ }^{80}$ one could claim that over time and in the long run disciplinary expertise and authority will be eroded by allowing the defense of stupid ideas. Simpson is correct to say that academic disciplines work best if experts "have certain communicative spaces and platforms within which the epistemic standards that define their discipline are stringent regulative ideals" because then those experts are not "being constantly taxed by their having to answer the complaints of people who do not recognize their expertise, or value the knowledge that it generates." 81 Astronomy and related fields would be ruined if all anyone ever did was respond to arguments for flat Earth theory. But the choice between the no platformer's position that flat Earth theory must never be publicly defended on campus and the view-held by no one but maybe some flat earthers - that the experts must "constantly" devote their time to responding to it is a false dilemma. Furthermore, since stupid ideas get traction outside the elite arenas of the professional journals and public skepticism of disciplinary expertise is partly driven by the fact that the experts tend to ignore them, it may be that addressing a stupid idea now and then is a better way to preserve and protect disciplinary expertise and authority than no platforming.

\section{Beyond the Horizon}

I find no strong epistemic reason to no platform the flat earther. But again, this is not to say that anyone should be required to invite someone to campus to defend this stupid theory. It is only to say that, if there is an interest in engaging with arguments for it on your campus and there are no countervailing practical or moral concerns, you should feel comfortable bringing a flat earther in if you want. People might even learn something.

Although there is a good bit of opposition to no platforming, we can expect the view advanced here to be controversial. Even among those who oppose prohibiting people like Bannon and Greer from publicly defending their views on campus, it will be hard to find many willing to say the same of the flat earther or to defend that line in the way done here. According to what Simpson calls the "standard view" 82 on the relation between academic freedom and free speech, universities are obligated protect and advance the integrity of teaching and research while simultaneously protecting freedom of expression by having different sets of rules for different realms of academic life. Erwin Chemerinsky and Howard Gillman, two university administrators and prominent advocates of free speech on campus, endorse the standard view and summarize it this way.

We should think of campuses as having two different zones of free expression: a professional zone, which protects the expression of ideas but imposes an

80 Simpson and Srinivasan, "No Platforming," 199.

81 Simpson, "The Relation Between Academic Freedom and Free Speech," 299.

82 Ibid., 288. 
obligation of responsible discourse and responsible conduct in formal educational and scholarly settings; and a larger free speech zone which exists outside scholarly and administrative settings where the only restrictions are those of society at large. ${ }^{83}$

On the standard view, the natural place to put a defense of flat Earth theory would be in the wild and woolly anything goes land of the non-academic free speech zone. But that is not the position taken here. I defend engagement with flat Earth theory not as a form of extra-curricular entertainment but as a way of advancing the university's academic mission.

Now let us see how the arguments offered here extend from flat Earth to other candidates for no platforming. In many ways, flat Earth theory should be an ideal case for the person who thinks there are good epistemic reasons in favor of no platforming. Flat Earth is a solid pick for the stupidest theory out there. ${ }^{84}$ So a case like this should be where we find the strongest possible epistemic basis for no platforming. When we turn our attention to other candidates for no platforming (e.g., Holocaust denial, anti-vaxxing, Sandy Hook conspiracy theory, QAnon), it is clear that flat Earth theory is at least as stupid as all of those, if not stupider. And therefore, if there is no good epistemic reason to no platform flat Earth theory, then there is no good epistemic reason to no platform any of those views either. And there is certainly no good epistemic reason to no platform views that are not stupid but merely controversial or offensive.

In response, one might contend that we are looking at this the wrong way. Maybe it oversimplifies things to think the epistemic case for no platforming gets better as the target theory gets stupider. Perhaps the best epistemic grounds for no platforming exist where the view in question is not so laughably stupid. One problem here is that, as the target theory gets less stupid, the case for engaging with arguments for it gets better because, as the plausibility of the dissenting opinion increases, so does the chance that the status quo opinion is wrong. And then the point of the first horn of Mill's dilemma gets sharper. Nonetheless, perhaps there an epistemic sweet spot for the no platformer, a range of views just plausible enough to be seductive to a wide audience but still stupid enough to provide a good epistemic basis for no platforming.

There is no reason to think any of the usual candidates for no platforming occupy the sweet spot. To see why, consider Levy's example of the "unreasonable minority" ${ }^{85}$ view of climate change skepticism. However unreasonable this minority view is, it is nowhere near as stupid as flat Earth theory. But the epistemic case for refusing to allow it to be defended on campus is no better. Levy's concern is that bringing a climate change skeptic in for a debate will generate misleading evidence that there is significant expert disagreement in this area and that will make it more rational for people to be less confident in climate change than they should be. But as with flat Earth theory, the higher-order evidence generated by holding this sort of event is not very strong and easily defeated. We can counter the impression that there is a wide degree of expert disagreement on this issue by, among other things, making it known (as Levy himself does) that "the consensus on climate change is very strong; roughly 97 percent of scientists with relevant expertise

83 Erwin Chemerinsky and Howard Gillman, Free Speech on Campus (New Haven, CT: Yale University Press, 2017), 77.

84 Flat Earth is arguably even stupider than Time Cube Theory. For, at least according to the latter, "in a single rotation of the Earth sphere [emphasis mine], each Time corner point rotates through the other 3-corner Time points." Wikipedia, https://en.wikipedia.org/wiki/Time_Cube.

85 Levy, "No-Platforming and Higher-Order Evidence," 488. 
accept it." ${ }^{86}$ And all of the other points made above still apply. Even if it is almost certainly false, there are numerous potential epistemic benefits to be had from engaging with arguments for climate change skepticism on campus and in the presence of the relevant experts. Refusing to engage with arguments for climate change skepticism on the grounds that those arguments might change your mind is a failure to follow the argument where it leads. No platforming the climate change skeptic as a means of preventing others from following the argument where it leads amounts to a problematic form of epistemic paternalism. And it is dubious that allowing experts to publicly engage with arguments for climate change skepticism on campus would undermine their disciplinary authority and it may even strengthen it. And once again, this is not to say anyone should be required to invite a climate change skeptic to campus if they do not feel like it.

The same points hold mutatis mutandis for all other candidates for no platforming. But many of those other views also carry moral implications. What is said here does not entail that we have no good reason to no platform these positions but that, if we do, our reasons are something other than epistemic. This would mean that, insofar as we are interested in the issue, we should focus our attention on moral or practical justifications for no platforming.

I end with some advice. Arthur Conan Doyle, a medical professional with a lucrative side gig, was famously duped into believing in the existence of spirits and fairies. Scientific training often does not prepare one to spot the tricks of a clever conman. That is why skeptical debunkers like Harry Houdini and James Randi insisted on assigning magicians (rather than scientists) to assess any alleged proof of the paranormal. There is an interesting analogy here. Many arguments for stupid ideas trade on subtle logical fallacies. Some creationist attacks on evolution, for instance, are really just disguised applications of old arguments for radical skepticism. Should you decide to bring someone in to defend flat Earth or any other stupid theory on campus, it is of course a good idea to have an expert scientist respond. But, if they are willing, it may be also good idea to put an expert in philosophy on the panel. They know the tricks.

86 Levy, "No-Platforming and Higher-Order Evidence," 496. 